\title{
A Pesquisa em Ensino de Astronomia para o Ensino Médio
}

\section{RESUMO}

Giselle Henequin Siemsen biologika@gmail,com orcid.org/0000-0002-0728-6633 Programa de Pós-graduação em Educação em Ciências e em Matemática, Curitiba, Paraná, Brasil

\section{Leonir Lorenzetti} leonirlorenzetti22@gmail.com Orcid.org/ 0000-0002-0208-2965 Departamento de Química, Programa de Pós-Graduação em Educação em Ciências e em Matemática, Curitiba, Paraná, Brasil.
O presente estudo tem como objetivo analisar a pesquisa em Ensino de Astronomia para o Ensino Médio, desenvolvida em programas de Pós-Graduação. Para esta análise, foi utilizada uma abordagem do tipo "Estado da Arte", a partir de trabalhos encontradas no Banco de Teses e Dissertações da Capes, voltados para o Ensino Médio. Foram averiguados, nesses documentos, principalmente a metodologia de pesquisa, o caráter disciplinar ou interdisciplinar, os conteúdos abordados e as relações estabelecidas a partir destes conteúdos. Com base nessa investigação, observou-se que todas as pesquisas são de Mestrado acadêmico ou profissional, com foco na sala de aula. Com relação aos conteúdos abordados, percebeu-se uma valorização da Física frente às demais disciplinas, com poucas relações com tópicos de outras áreas do conhecimento, indicando lacunas, principalmente quanto aos conteúdos de química. Desta forma, a maioria dos trabalhos são classificados como disciplinares, confrontando as orientações dos PCN e PCN+. Concluiu-se, então, que há a necessidade de um enfoque interdisciplinar mais sólidos nas pesquisas em Ensino de Astronomia para o Ensino Médio, considerando principalmente a inclusão de conteúdos de Química.

PALAVRAS-CHAVE: Ensino de Astronomia. Ensino Médio. Interdisciplinaridade. Química. 


\section{INTRODUÇÃO E CONTEXTUALIZAÇÃO}

Desde os primórdios da humanidade há um fascínio e um profundo interesse pela Astronomia. Com relação ao ensino, a astronomia é considerada, pela matriz curricular proposta pelos Parâmetro Curriculares Nacionais (PCN) (BRASIL, 1999) e Parâmetros Curriculares Nacionais para o Ensino Médio (PCN+) (BRASIL, 2002), um campo de conhecimento indispensável à compreensão do "lugar" que o ser humano ocupa na história do Universo. Com esse conhecimento, o indivíduo pode desenvolver um olhar mais amplo, ampliar os seus horizontes, enquanto busca saber mais. Esse movimento leva a um processo de ensino e de aprendizagem capaz de romper fronteiras, fazendo com que o aluno se aproprie de sua vida através do conhecimento (BRASIL, 1999).

No Ensino Superior, segundo Langhi e Nardi (2010) e Bretones (1999), cerca de 54 cursos de graduação contemplam disciplinas específicas de astronomia, sendo que, nos cursos de licenciatura, esses conteúdos estão ausentes ou defasados. Como consequência, os professores não adquirem uma formação sólida sobre esta temática a ensinam astronomia, muitas vezes, de forma resumida e incorreta. Um reflexo disso são os conteúdos abordados em sala de aula, no Ensino Fundamental, que se restringem à uma abordagem simplificada do sistema solar, bem como os movimentos da Terra e os modelos Geocêntrico e Heliocêntrico, conteúdos esses, trabalhados quase que somente nas disciplinas de Ciências e Geografia (LANGHI; NARDI, 2007; DIAS; RITA, 2008; MOTA; BONOMINI; ROSADO, 2009).

Com relação ao Ensino Médio, os $\mathrm{PCN}+$ incorporam a astronomia à disciplina de física, no eixo estruturador "Universo, Terra e Vida", apesar de reconhecê-la como interdisciplinar por natureza, por possuir interfaces com disciplinas tais como biologia, física, química, história, geografia, entre outras (BRASIL, 2002).

Além destas relações disciplinares, o ensino de astronomia, em todo o seu contexto, pode propiciar a compreensão da natureza como processo dinâmico e do conhecimento histórico do processo de desenvolvimento das ciências (DIAS; RITA, 2008). O trabalho dessas relações em sala de aula pode atuar como um agente transformador ao mesmo tempo em que possibilita a utilização de conhecimentos científicos para explicar o funcionamento do mundo, desenvolver modelos explicativos para sistemas tecnológicos e planejar e avaliar as interações homem-natureza (DIAS; RITA 2008; BRETONES, 1999; LANGHI; NARDI, 2009). Essas visões contribuem para uma abordagem mais contextualizada e, consequentemente, menos fragmentada do conhecimento científico (DIAS; RITA, 2008).

Langhi (2011) identificou, em seus estudos, alguns dos principais problemas relacionados ao Ensino de Astronomia no Brasil. Entre eles, estão a lacuna na formação inicial de professores da educação básica, cursos de formação continuada que não impactam a prática dos docentes, carência de material bibliográfico com linguagem acessível, espetacularização excessiva da mídia sobre fenômenos da astronomia, persistência de erros conceituais em livros didáticos, quantidade reduzida de pesquisas voltadas para o ensino de astronomia, perda de valorização cultural, entre outros.

Para solucionar alguns desses problemas, nos últimos anos, algumas pesquisas têm sido elaboradas para intensificar os esforços para que a Astronomia 
seja inserida no contexto escolar, em especial, no Ensino Médio, de forma ampla, contextualizada e aprofundada, evitando assim que se torne apenas uma ciência para curiosos ou especialistas (LANGHI; NARDI, 2010; DIAS; RITA, 2008; MOTA; BONOMINI; ROSADO, 2009).

Para esse fim, pode-se fazer uso de abordagens contextualizadas, discutindo questões mais complexas, que envolvem Ciência, Tecnologia e Sociedade (CTS) e a Alfabetização Científica e Tecnológica (ACT) (AIKENHEAD, 1994; CHASSOT, 2000; BOCHECO, 2011, LORENZETTI; SIEMSEN; OLIVEIRA, 2017). Discussões abordando História e Filosofia da Ciência (MATTHEWS, 1995) ou propostas interdisciplinares podem motivar os alunos e propiciar um ambiente para aprimoramento do pensamento crítico, podendo até melhorar a assimilação de conteúdos em virtude de múltiplas conexões desenvolvidas (KLEIN, 2008).

Nesse contexto, as práticas interdisciplinares podem ser encaradas como uma possibilidade de articulação de um todo com as partes, amarrando os meios com os fins, construindo-se de modo que todas as disciplinas envolvidas são consideradas importantes, sem que exista uma hierarquia entre elas (LENOIR, 2008). Fazenda (2005) e Severino (2008) defendem ainda que para o desenvolvimento de uma prática interdisciplinar é preciso optar por metodologias inovadoras, que rompam com a desarticulação da vida escolar com a vida do aluno.

Com base nas questões discutidas acima, algumas questões, recorrentes de pesquisas bibliográficas do tipo "estado da arte" (FERREIRA, 2002), podem ser levantadas: Como se situa a Pesquisa no Ensino de Astronomia, voltada para o Ensino Médio, no contexto nacional? Que dimensões desse ensino tem sido investigada? Que conteúdos têm sido privilegiados? Que estratégias metodológicas são mais utilizadas pelos pesquisadores? Como a interdisciplinaridade tem sido desenvolvida nestas pesquisas?

Para responder a esses questionamentos, é necessário realizar um estudo que sistematize a produção acumulada. Esta investigação permite ver de forma mais ampla a área e suas tendência, dando visibilidade ao já realizado, ordenando os dados e assim, propiciando uma reflexão crítica sobre o campo de conhecimento (FERREIRA, 2002). Estudos desse tipo, denominado "estado da arte" ou "estado do conhecimento" (FERREIRA, 2002), trazem contribuições significativas ao desenvolvimento de uma ciência.

A partir disso, o presente estudo analisa e sistematiza dados que indicam o perfil da Pesquisa em Ensino de Astronomia no Ensino Médio, presentes em dissertações de mestrado e teses de doutorado presentes no Banco de Teses e Dissertações da Capes, no período compreendido entre 1999 a 2016.

\section{METODOLOGIA}

O objetivo do presente estudo é analisar e caracterizar a pesquisa em Ensino de Astronomia voltada para o Ensino Médio. Para isso, foi realizada uma pesquisa bibliográfica caracterizada como do tipo "estado da arte" (FERREIRA, 2002). Os dados foram coletados no Banco de Teses e Dissertações da Capes, utilizando para a busca os termos "Ensino de Astronomia".

Os dados foram identificados e analisados a partir da leitura da introdução, metodologia e considerações finais de cada trabalho e caracterizados quanto ao 
ano de produção, instituição de origem, tipo de documento, metodologia de pesquisa, caráter disciplinar ou interdisciplinar, conteúdo abordado, relações estabelecidas com outras áreas, foco, público alvo, estratégias utilizadas e contribuições observadas a partir do ensino de astronomia.

\section{A PESQUISA EM ENSINO DE ASTRONOMIA NO ENSINO MÉDIO}

A partir da busca por pesquisas em Ensino de Astronomia, foram encontrados 106 trabalhos. Destes, apenas 27 são voltados para o Ensino Médio, distribuídos entre os anos de 2005 e 2016, conforme indica o Quadro 1.

Quadro 1 - Número de trabalhos por ano.

\begin{tabular}{ll}
\hline Ano & Número de trabalhos \\
\hline 2015 & 10 \\
\hline 2005 & 3 \\
\hline 2014 & 3 \\
\hline 2007 & 2 \\
\hline 2008 & 2 \\
\hline 2012 & 2 \\
\hline 2013 & 2 \\
\hline 2006 & 1 \\
\hline 2011 & 1 \\
\hline 2016 & 1 \\
\hline
\end{tabular}

Fonte: Autoria Própria (2017).

Com base nos dados é possível perceber que não há um crescimento linear no número de trabalhos ao longo dos anos. Entre 2005 e 2007, o número de pesquisas diminuiu de três para dois. No ano de 2008, no total, duas dissertações foram produzidas. Em 2009 e 2010, não foram desenvolvidas pesquisas nessa temática. Por fim, de 2011 em diante, há um crescimento de estudos, passando de um para três em 2014 e dez em 2015. Até o presente momento, existe apenas um trabalho publicado no Banco de Teses e Dissertações da Capes em 2016, número que pode ser alterado conforme os trabalhos forem disponibilizados na plataforma.

Estas pesquisas foram desenvolvidas em 15 instituições de Ensino Superior, conforme indicado no Quadro 2.

Quadro 2-Número de trabalhos por Instituição.

\begin{tabular}{ccc}
\hline Instituição & Estado & $\begin{array}{c}\text { Número de } \\
\text { trabalhos }\end{array}$ \\
\hline Universidade Federal do Rio Grande do Sul & Rio Grande do Sul & 6 \\
\hline Universidade Federal do Rio Grande do Norte & Rio Grande do Norte & 3 \\
\hline Universidade de São Paulo & São Paulo & 3 \\
\hline Universidade Estadual de Feira de Santana & Bahia & 3 \\
\hline
\end{tabular}




\begin{tabular}{ccc}
\hline Instituição & Estado & $\begin{array}{c}\text { Número de } \\
\text { trabalhos }\end{array}$ \\
\hline Universidade de Brasília & Brasília & 2 \\
\hline Universidade Cruzeiro do Sul & São Paulo & 1 \\
\hline Universidade Federal do Vale do São Francisco & Pernambuco & 1 \\
\hline Universidade Estadual Paulista & São Paulo & 1 \\
\hline Universidade Federal do Espírito Santo & Espírito Santo & 1 \\
\hline Universidade Federal de Itajubá & Minas Gerais & 1 \\
\hline Centro Universitário Franciscano & Rio Grande do Sul & 1 \\
\hline Universidade Federal do Pará & Pará & 1 \\
\hline Universidade de Caxias do Sul & Rio Grande do Sul & 1 \\
\hline Universidade Federal de São Carlos & São Paulo & 1 \\
\hline Instituto Federal de Educação Científica e & Goiás & 1 \\
\hline Tecnológica de Goiás & & \\
\hline
\end{tabular}

Fonte: Autoria Própria (2017).

Estes dados indicam que, considerando as universidades citadas, 8 trabalhos foram desenvolvidos no estado do Rio Grande do Sul, enquanto que 6 foram originados em São Paulo. Esses dados confrontam as observações feitas por Lorenzetti (2008), Francisco (2011) e Silva e Queiroz (2013), que indicavam uma presença mais significativa de pesquisa na região sudeste, uma vez que nesta região há uma concentração maior de programas de pós-graduação. Entretanto, é importante ressaltar que no presente estudo, o olhar está sobre as dissertações voltadas para o Ensino Médio. Em um estudo anterior de Siemsen e Lorenzetti (2017), observou-se que, com relação à pesquisa no Ensino de Astronomia de forma geral, considerando todos os níveis de ensino, os dados seguem o padrão observado por Lorenzetti (2008), Francisco (2011) e Silva e Queiroz (2013).

Outro ponto analisado foi o tipo de documento, classificado como de Mestrado Acadêmico, Mestrado Profissional ou Doutorado. Observou-se que 16 trabalhos desenvolvidos são de Mestrado Profissional, enquanto que 11 são de Mestrado Acadêmico. Nenhuma das pesquisas analisadas estava vinculada a um curso de Doutorado. Essa análise demonstra que existe uma produção significativa em programas de pós-graduação na área de Ensino de Astronomia em nível de Mestrado no contexto nacional, porém, estas pesquisas não são levadas adiante para culminarem em teses de Doutorado, o que pode levar a um não aprofundamento teórico e prático nesta temática.

Em todas as pesquisas analisadas (27), o foco se deu na sala de aula de Ensino Médio. Destas, vinte e duas foram voltadas para os alunos, enquanto que cinco foram desenvolvidas com professores, em processos de formação continuada.

Em seguida, foram analisadas as metodologias de pesquisa utilizadas pelos pesquisadores. Tais metodologias foram categorizadas e serão apresentadas a seguir:

a) Sequência didática:

Foram agrupadas nesta categoria oito trabalhos, que indicaram explicitamente que fariam uso de sequências ou unidades didáticas (COSTA, 2015; 
MORETTI, 2012; RODRIGUES, 2015; JESUS, 2015; SILVA, 2015; SANTIAGO, 2015; ABREU, 2015; SILVA, 2015). Esta metodologia é o cerne do estudo e está diretamente relacionada com o planejamento de aulas, em consonância com um problema e um referencial teórico, ao mesmo tempo em que se articula com os instrumentos de constituição de dados e o objetivo da pesquisa. Portanto, não se trata de aulas desconexas e sem nenhuma intencionalidade. E é a partir disso que potencialidades e limitações podem ser avaliadas, de modo que o estudo se torna, ao mesmo tempo, fonte de consulta e possibilidades para demais professores e de contribuições para a área em questão (ZABALA, 1998).

É possível afirmar, a partir dos dados, que a utilização dessa metodologia tem uma grande representatividade no Ensino de Astronomia. Uma sequência didática bem estruturada pode levar ao desenvolvimento de uma prática interdisciplinar eficaz, conforme defende Fazenda (2005) e Severino (2008), além de motivar o aluno, despertar o interesse para as temáticas trabalhadas, alcançar níveis mais profundos de contextualização, relações CTS e pensamento crítico (KLEIN, 2008).

b) Aulas:

Em contraposição ao que foi discutido no tópico anterior, sete trabalhos analisados indicaram a ausência de uma metodologia específica, utilizando apenas aulas (ALBRECHT, 2008; COSTA, 2005; KEMPER, 2008; NEITZEL, 2006; LEÃO, 2012; VALENTE, 2007; SILVA, 2011). De forma antagônica à sequência didática, as aulas expositivas-dialogadas por si só não inferem uma articulação com contextos ou recursos, de modo que se recai no pensamento de metodologia tradicional.

Tais aulas são desenvolvidas em uma sucessão de momentos, no qual os conteúdos são desenvolvidos de forma linear, com uso de recursos como quadro e giz.

É importante destacar que, apesar do grande número de trabalhos que adotaram essa perspectiva de ensino, essa metodologia já vem sendo criticada e, em muitos casos, substituída por outros métodos.

c) Produção de Materiais:

Quatro trabalhos foram classificados em relação à produção de materiais (SCHMITT, 2005; PEREZ, 2015; ARAÚJO, 2014; CARRILHO, 2015). Esta produção ocorreu com a participação dos pesquisadores e dos alunos, pelo menos em um dos momentos da pesquisa, a fim de elaborar caderno de experimentos, caderno de atividades do aluno, caderno de atividades do professore e kits experimentais.

Estas ações indicam a preocupação dos pesquisadores em fazer com que os alunos envolvidos participem do processo de ensino e de aprendizagem e que assumam o papel de protagonistas, de forma colaborativa.

De forma análoga ao que foi discutido no primeiro item, esta metodologia pode ser caracterizada como fonte de estudo para outros professores e pode contribuir de forma efetiva para a delimitação de avanços na área de Ensino de Astronomia, de forma geral.

d) Oficina/curso para professores:

Em três trabalhos o foco foi a elaboração e aplicação de oficinas ou cursos para professores, em processos de formação inicial e/ou continuada (COSTA, 2005; 
COSTA 2015; SOBRINHO, 2005). Por não se tratar de um ambiente convencional de sala de aula, estas pesquisas não foram categorizadas como sequência didática.

Nestes trabalhos, ficou evidente a preocupação dos pesquisadores em instrumentalizar professores para trabalhar com alunos de Ensino Médio, com o objetivo de inserir a Astronomia na sala de aula.

Ações como essas são importantes para amenizar o problema da defasagem ou ausência de conteúdos de Astronomia nas licenciaturas, apontados por Langhi e Nardi (2009).

e) Curso de extensão/oficina para os alunos:

De forma semelhante ao que foi discutido no tópico anterior, duas pesquisas foram desenvolvidas com base em cursos e/ou oficinas para alunos, em contextos diferentes daqueles comuns à sala de aula (SILVA, 2016; GONÇALVES, 2014).

A aplicação de oficinas se deu principalmente por conta de dificuldades encontradas no âmbito escolar e que impediram o desenvolvimento de sequências didáticas em aulas regulares. Assim, as atividades foram realizadas em períodos de contra turno, nos quais os alunos foram convidados a participarem. Nesses casos, os encontros tiveram duração maior do que uma hora/aula.

A aplicação de cursos se deu em contextos de extensão, em escola técnica e com o foco na preparação para a Olimpíada Brasileira de Astronomia (OBA), distanciando-se da realidade escolar que representa o foco deste trabalho.

f) Curso à distância:

Outra importante metodologia de pesquisa adotada foi a elaboração e aplicação de cursos em ambiente virtual, em uma dissertação (MOTA, 2013).

A utilização de tecnologias digitais é essencial para o Ensino de Astronomia, uma vez que se trata de conteúdos gerais de difícil visualização pelos alunos. Desta forma, recursos tecnológicos podem ser utilizados como ferramentas que auxiliam no processo de ensino-aprendizado.

Nesses casos, optou-se por unir tais recursos com o Ambiente Virtual de Aprendizagem (AVA), em cursos à distância, com alunos do Ensino Médio.

g) Desenvolvimento de jogos:

Ao todo, um trabalho utilizou como metodologia de pesquisa o desenvolvimento e aplicação de jogos (SILVA, 2014). Nestes casos, o conteúdo é trabalhado de forma lúdica e que foge ao tradicionalismo.

Novamente, a participação dos alunos durante o processo é relevante, por colocá-lo como integrante da pesquisa e da aprendizagem, como protagonista e não como mero espectador.

A abordagem lúdica se materializa, também, como uma metodologia inovadora, que, dentro de um contexto, pode vir a corroborar uma prática interdisciplinar, conforme defende Fazenda (2005) e Severino (2008).

Em um trabalho, a metodologia de pesquisa não ficou clara e não associava o problema de pesquisa com os objetivos propostos. Trata-se de uma pesquisa na qual se propôs a realização de análises empíricas, mas houve apenas um tratamento teórico de tópicos de Astronomia. 
Outro foco do presente estudo se deu na classificação do caráter das pesquisas, denominados disciplinares ou interdisciplinares, de acordo com o que foi indicado no corpo do texto das dissertações e o que foi desenvolvido nas atividades. Os dados estão organizados no Quadro 3.

Quadro 3 -Caráter das atividades desenvolvidas em casa pesquisa.

\begin{tabular}{cc} 
Caráter das atividades & Número de trabalhos \\
\hline Disciplinar- Física & 22 \\
\hline Interdisciplinar- Física e Geografia & 2 \\
\hline Interdisciplinar- Física, Biologia e Química & 1 \\
\hline Interdisciplinar- Física e Matemática & 1 \\
\hline Interdisciplinar- Física Moderna e Astronomia & 1 \\
\hline
\end{tabular}

Fonte: Autoria Própria (2017).

A partir dos dados acima, é possível afirmar que a maioria dos trabalhos (22) apresenta um caráter disciplinar. Apenas três pesquisas apresentaram interface da astronomia com áreas não afins à física (duas com Geografia e uma com Biologia e Química). Um estudo fez inter-relações com a Matemática e outro com a Física Moderna.

Esse panorama aponta para uma incoerência entre a interdisciplinaridade defendida pelos PCN (BRASIL, 1999) e PCN+ (BRASIL, 2002), referenciais utilizados em todos os estudos, e a prática adotada pelos pesquisadores. Em outras palavras, as atividades propostas na maioria das dissertações avaliadas ainda não estão em consonância com o que é entendido por Astronomia, de forma geral.

Conforme defende Lenoir (2008), a interdisciplinaridade não compreende a hierarquização de uma disciplina frente a outra. Entretanto, o que se observa nas dissertações é um Ensino de Astronomia totalmente voltado para a Física, com algumas relações com conceitos de outras áreas do conhecimento. Neste caso, até mesmo trabalhar com Física Moderna pode não significar um movimento interdisciplinar, uma vez que esta é uma das bases para o entendimento atual do Universo.

Essas lacunas indicam ainda que o entendimento do termo e das implicações da interdisciplinaridade não está totalmente entendido e incorporado pelos pesquisadores, o que afasta as suas práticas do que propõem Fazenda (2005), Severino (2008), Lenoir (2008) e Klein (2008).

Além do caráter das pesquisas, faz-se importante analisar também os conteúdos abordados nas atividades propostas pelos autores, indicados no Quadro 4.

Quadro 4-Conteúdos abordados nas pesquisas.

Conteúdos abordados

Página | 192
Número de trabalhos

7

6

3

2 


\begin{tabular}{cc}
\hline Conteúdos abordados & Número de trabalhos \\
\hline Mecânica & 1 \\
\hline Dinâmica Celeste & 1 \\
\hline Lei da Gravitação Universal de Newton & 1 \\
\hline Gravidade e Luz & 1 \\
\hline Dias e noites & 1 \\
\hline Sol & 1 \\
\hline Vida e elementos químicos & 1 \\
\hline Coordenadas geográficas & 1 \\
\hline Etnoastronomia & 1 \\
\hline
\end{tabular}

Fonte: Autoria Própria (2017).

O estudo do Sistema Solar está presente em sete dissertações, corroborando as ideias defendidas por Langhi e Nardi (2007), de que este é um dos conteúdos mais amplamente abordado em sala de aula da Educação Básica.

Tópicos de astronomia, de forma geral, foram indicados em seis estudos. Conteúdos como Big-Bang, diferenças entre planetas e estrelas, gravidade e outros, foram desenvolvidos em sala de aula, sem inferências diretas explicitadas pelos autores, da astronomia com conteúdos específicos de física ou outras disciplinas.

De forma contrária, em três pesquisas, as atividades desenvolvidas foram trabalhadas com base na física, de modo geral, sem a delimitação de conteúdos específicos desta disciplina. Vale ressaltar que todas pesquisas são dissertações de mestrado e, portanto, a parte empírica do processo não ultrapassou o período de um ano letivo. Assim sendo, nenhuma proposta, seja de aula ou de atividade, abordou todo o conteúdo de física do Ensino Médio, e certamente, houve a preferência por alguns tópicos em detrimento de outros.

Conteúdos clássicos da Física, tais como Energia (2), Mecânica (1), Lei da Gravitação Universal (1) e Gravidade e luz (1) foram apresentados de forma bem delimitada, deixando claro de que maneira as atividades seriam desenvolvidas a partir dessas temáticas.

De forma semelhante, Dinâmica celeste (1), Dias e noites (1) e Sol (1) são temáticas referentes à Astronomia

Porém, como abordado na discussão anterior, nesses casos há uma valorização de uma disciplina frente as outras, rompendo com os pressupostos de uma prática interdisciplinar, como defendido por Lenoir (2008), Fazenda (2005) e Severino (2008). Esses dados estão de acordo com o que já foi discutido, anteriormente, com relação ao caráter disciplinar ou interdisciplinar das pesquisas desenvolvidas.

Em um trabalho os pesquisadores citaram o conteúdo de origem dos elementos químicos leves, porém, essa relação não aparece de forma concreta no desenvolvimento das atividades propostas. Também, nesses casos, não há a indicação de textos, artigos, vídeos ou demais recursos para a abordagem deste tema. 
Apesar de entender que a Astronomia é uma ciência que apresenta relação claras com a Biologia, a Geografia e a Química, conforme defendem os PCN+ (BRASIL, 2002), é possível perceber a ausência de atividades ou discussões envolvendo tópicos da química, em todos os trabalhos analisados. Essa defasagem pode ocorrer pela inexistência de disciplinas ou conteúdos de astronomia na formação de professores, como defendido por Bretones (1999) e Langhi e Nardi (2010). O reflexo direto disso é um ensino de Astronomia fragmentado e isolado apenas na disciplina de Física.

Foram trabalhados também conteúdos que abordavam coordenadas geográficas (1) e etnoastronomia com base na astronomia indígena brasileira (1). Essas pesquisas se distanciam das demais por apresentar no corpo do texto uma preocupação dos autores em trabalhar a astronomia a partir de temáticas nem sempre óbvias e que se estabelecem em outros campos do conhecimento, que não a física. As atividades que propuseram relações com tópicos de biologia, química, geografia e cultura indígena se encaixam em um caráter que se aproxima da interdisciplinaridade, defendida por Fazenda (2005), Severino (2008) e Lenoir (2008), mesmo que isso não seja indicado no corpo do texto dos documentos ou não seja necessariamente o foco da pesquisa.

Analisou-se também se estes conteúdos abordados estabeleceram relações com outras áreas do conhecimento. Os dados estão indicados no Quadro 5.

Quadro 5 - Relações estabelecidas nas pesquisas.

\begin{tabular}{cc}
\hline Relações & Número de trabalhos \\
\hline Não consta & 13 \\
\hline História e Filosofia da Ciência & 3 \\
\hline Religião, cultura e mitologia & 2 \\
\hline Com a física em si & 2 \\
\hline Localização e tecnologias & 2 \\
\hline Física moderna (quântica) & 1 \\
\hline Formação do Universo e origem da vida & 1 \\
\hline História da Astronomia e tecnologia & 1 \\
\hline História da astronomia & 1 \\
\hline Matemática e Engenharia & 1 \\
\hline
\end{tabular}

Fonte: Autoria Própria (2017).

Esta análise está diretamente relacionada com os dois tópicos já discutidos: o caráter disciplinar ou interdisciplinar das pesquisas e os conteúdos estruturantes abordados.

Para que um estudo seja de cunho interdisciplinar, é necessário que apareçam relações destes conteúdos estruturantes com outras temáticas, presentes em outras áreas de conhecimento, mesmo que de forma menos estrita e equivalente, fator que foi analisado no item anterior.

Em 13 dissertações não foram encontradas relações entre o conteúdo principal desenvolvido nas atividades com elementos de outras disciplinas ou com histórico, contexto ou cultura. Nesses trabalhos, houve a preocupação restrita de 
abordar a astronomia a partir de um único ponto de vista, em sua maioria, científico e físico. Mais uma vez, fica evidente a ausência de uma prática interdisciplinar por parte dos pesquisadores no andamento de seus trabalhos, o que confronta as ideias defendidas por Lenoir (2008), Fazenda (2005) e Severino (2008).

Em duas pesquisas observou-se relações da física com a própria física, ou seja, diálogo de um conteúdo específico com outro. Porém, é importante ressaltar que, mesmo que esse diálogo seja importante para o aprendizado do aluno, isso não se caracteriza como uma relação de interdisciplinaridade, pois, como afirma Lenoir (2008) "uma prática interdisciplinar gera uma articulação do todo com as partes [...] de modo que todas as disciplinas são consideradas importantes", indicando que, nessa abordagem, não é possível que exista apenas uma área do conhecimento sendo trabalhada.

Nos demais estudos, foi possível identificar algumas relações, tais como religião, cultura e mitologias (2), localização e tecnologias (2), física moderna (1), origem da vida (1), História da Astronomia e tecnologias (1), História da Astronomia (1), Matemática e Engenharia (1). Nesses casos, é possível perceber que há um movimento levando para uma intencionalidade interdisciplinar, ou seja, alguns avanços são feitos para superar a fragmentação e a separação do ensino em disciplinas totalmente separadas e que não se conversam entre si.

Esses avanços são de grande importância no cenário do Ensino de Astronomia e na pesquisa em Ensino de Ciências de forma mais abrangente, por começarem a trilhar um caminho pela qual futuros pesquisadores e professores possam aproveitar elementos para dar continuidade a essas pesquisas ou desenvolver uma prática interdisciplinar em sala de aula, que esteja de acordo com os pressupostos defendidos por Lenoir (2008), Fazenda (2005), Severino (2008) e Klein (2008).

As estratégias ou recursos utilizados pelos autores em suas pesquisas empíricas na abordagem das aulas e atividades também foram analisadas. Essa observação permitiu perceber que as atividades foram desenvolvidas com base em mais de um recurso simultaneamente, na maioria dos casos, estando os dados indicados no Quadro 6.

Quadro 6-Estratégias utilizadas nas atividades aplicadas nas dissertações.

\begin{tabular}{cc}
\hline Estratégias & Número de trabalhos \\
\hline Experimentação & 8 \\
\hline Slides & 6 \\
\hline Modelos e maquetes & 6 \\
\hline Textos & 5 \\
\hline Vídeos & 5 \\
\hline Planetários & 5 \\
\hline Desenvolvimento de materiais & 4 \\
\hline Observação do céu & 3 \\
\hline Aplicativos/softwares & 3 \\
\hline Jogos & 2 \\
\hline Seminários & 1 \\
\hline
\end{tabular}




\begin{tabular}{cc}
\hline Teatro & 1 \\
\hline Filme & 1 \\
\hline AVA & 1 \\
\hline Simuladores & 1 \\
\hline Realidade aumentada & 1 \\
\hline Somente aulas & 1 \\
\hline
\end{tabular}

Fonte: Autoria Própria (2017).

As experimentações, do tipo demonstrativa ou experimentação problematizadora (FRANCISCO JR; FERREIRA; HARTWIG, 2008) relacionadas aos Três Momentos Pedagógicos, foram citadas em oito trabalhos, indicando o quanto este recurso ainda é predominantemente utilizado em sala de aula, em especial no ensino de Ciências.

O uso de projetor de multimídia e slides permeou seis dissertações, enquanto que a utilização de aplicativos e softwares foi contabilizada em três pesquisas. Foram encontrados ainda o uso de simuladores (1) e realidade aumentada (1). Nesse ponto é importante ressaltar que, uma vez que a Astronomia trata de assuntos que, muitas vezes, são de difícil visualização, faz-se necessário o uso de imagens, simulações e modelos digitais para a compreensão de fenômenos não visíveis a olho nu.

A construção de modelos e maquetes, normalmente em escala de tamanho e distância, foram citadas em seis trabalhos, enquanto que o desenvolvimento de materiais, teóricos e experimentais apareceu em quatro casos. Estas propostas de construção pelo aluno podem levar ao entendimento de situações complexas, como por exemplo, de unidades de medida, superfície da Lua e posicionamento dos planetas no sistema solar. Desse modo, há uma melhor compreensão visual destes conteúdos por parte do aluno, bem como se aprimora a participação e o envolvimento deste com as atividades, com os demais colegas e com o professor, além de fugir da metodologia tradicional de quadro e giz.

O uso de textos, vídeos e visitas a planetários estiveram presentes em cinco trabalhos, cada uma. Novamente, o uso de reportagens ou textos científicos, as imagens e simulações nos vídeos e as visualizações nos locais propícios para os estudos de Astronomia possibilitam ao aluno a prática da leitura e da imaginação, ao mesmo tempo em que favorece o desenvolvimento de um pensamento crítico, uma visão mais ampla dos assuntos trabalhos e até mesmo a superação de conceitos errôneos.

Em três trabalhos, optou-se por realizar observações do céu, com ou sem telescópios. É importante ressaltar que estas foram as atividades que inicialmente deram origem ao que hoje se entende por Astronomia, ou seja, são situações carregadas de um forte fator filosófico e histórico que pode e deve ser abordado em sala de aula, fator esse que não foi abordado em nenhuns dos estudos que se propôs a realizar observações do céu.

A utilização de jogos foi indicada em dois casos, sendo que em um trabalho houve o desenvolvimento e a aplicação do recurso e, em outro, somente a aplicação com os alunos. 
Estratégias como apresentação de seminários (1), apresentação de uma peça de teatro (1), assistir um filme com temas de Astronomia (1) e aulas em um Ambiente Virtual de Aprendizagem (AVA) (1), também, foram utilizadas pelos autores em suas pesquisas, porém, em poucos casos.

Todos os recursos citados indicam que as atividades propostas nas dissertações superaram, em princípio, as práticas tradicionais em sala de aula, uma vez que há a procura de mais de uma estratégia de ensino, simultaneamente, bem como a articulação destas com as aulas nas sequências didáticas, cursos e oficinas propostas. Essa busca por metodologias inovadoras está diretamente atrelada com uma postura que pode levar à construção de uma prática interdisciplinar por parte dos pesquisadores/professores, como defende Fazenda (2005) e Severino (2008), e, assim, gerar uma melhoria no Ensino de Astronomia como um todo

Por fim, foi possível observar ainda que, em uma dissertação a estratégia utilizada pelo pesquisador foi unicamente as aulas tradicionais. Esse dado mostra que, mesmo que exista um movimento em busca de metodologias mais eficazes em sala de aula, ainda há a persistência de um pensamento tradicional, que nada têm a contribuir com o panorama existente na Educação Básica.

A última análise realizada deu-se em relação as contribuições do Ensino de Astronomia. Em outras palavras, observou-se em que sentido as propostas de Ensino de Astronomia trouxeram novas perspectivas e contribuições para a sala de aula. Cada pesquisa citou, em média, pelo menos duas contribuições distintas e, as principais são discutidas a seguir.

a) Motivação:

O fator motivacional foi apontado em 17 trabalhos. Uma vez que a Astronomia é uma ciência que, muitas vezes, é suprimida dos currículos e da sala de aula, como defendido por Langhi e Nardi (2009), a possibilidade de desenvolvimento de atividades que façam relações do conteúdo com estes tópicos pode despertar o interesse do aluno. Conforme descrito nos PCN (BRASIL, 1999) e PCN+ (BRASIL, 2002), o ensino de Astronomia propicia a compreensão do seu lugar no Universo, assim como a ampliação de horizontes para o aluno, fatores que muitas vezes são deixados em lado em um ensino memorístico e sem relações com o cotidiano dos estudantes.

Com bases nos dados, é possível afirmar então que a abordagem de assuntos que despertam o interesse e a criatividade dos alunos, em conjunto com as metodologias e recursos diferenciados em sala de aula motivam os indivíduos, fazendo com que estes apresentem maior desempenho, participação e comprometimento com o ensino.

Tendo como base que em muitas das dissertações há uma evidenciação de problemas no ensino de física, em especial, devido à falta de interesse dos alunos, o ensino de Astronomia inovador e interdisciplinar se consolida com uma estratégia eficaz para reaproximar os estudantes com os conteúdos ensinados em sala de aula, solucionando alguns destes desafios.

b) Melhoria do aprendizado do aluno:

Uma vez que o aluno se sinta mais motivado a aprender, é de se esperar que 
É importante ressaltar que nem todas as dissertações tinham como objetivo observar o aprendizado dos alunos, portanto, é possível que isso justifique o fato dessa característica não ter sido indicada mais vezes. Porém, tendo em vista os amplos problemas educacionais enfrentados na educação e, em especial no ensino de física, novamente estes dados são expressivos na defesa do Ensino de Astronomia como possibilidade de melhoria da aprendizagem como um todo.

Conforme discutido anteriormente, a articulação da curiosidade e criatividade do aluno com assuntos que despertem o seu interesse, quando em aulas diferenciadas, propicia um melhor ambiente de aprendizado de conteúdos, bem como o desenvolvimento de outras características, tais como o pensamento crítico e a incorporação de conhecimentos científicos que impactem o seu cotidiano.

c) Aprimoramento das relações pessoais dos alunos em sala de aula:

Uma vez que muitas das atividades propostas nas dissertações possibilitavam trabalhos ou discussões em grupo, como no caso das construções de modelos e maquetes ou a utilização de jogos, os pesquisadores observaram, em três trabalhos, o aprimoramento das relações pessoais dos alunos em sala de aula.

Nesse sentido, mais uma vez, o ensino de astronomia em uma perspectiva que foge ao tradicionalismo educacional, permite avanços que vão além dos fatores educacionais e impactam outros setores da vida do aluno, como as relações interpessoais em sala de aula.

d) Autonomia dos alunos:

Ainda com relação à quebra do tradicionalismo em sala de aula, as propostas diferenciadas das dissertações possibilitaram ao aluno o desenvolvimento de uma autonomia, indicada em dois trabalhos.

O movimento pelo qual o aluno deixa de ser um mero receptor de conteúdos e passa a ser protagonismo do seu aprendizado caracteriza o crescimento da autonomia do indivíduo. Como discutido anteriormente, todos os fatores já abordados até o momento influenciam em situações que, em um panorama geral, demonstram avanços e contribuições pertinente no processo de ensinoaprendizagem.

f) Aprimoramento das relações professor-aluno

Corroborando a discussão realizada no item "c", uma das contribuições explicitadas nos trabalhos foi o aprimoramento das relações entre o professor e o aluno evidenciado em dois trabalhos.

Com base nos mesmos pressupostos já apresentados, pode-se afirmar que atividades realizadas em perspectivas diferenciadas, com conteúdos que sejam interessantes para os alunos, permitem uma dialogicidade maior entre os entes envolvidos no processo de ensino e de aprendizagem. Esse fator pode também impactar, juntamente com todos os pontos já demonstrados, e facilitar a aprendizagem do aluno e, também, nesse caso, o ensino pelo professor.

g) Aprendizagem significativa e construção significativa de conceitos:

Algumas dissertações tinham como objetivo proporcionar ao aluno uma aprendizagem significativa, segundo as teorias de Ausubel (MOREIRA, 1999). Esta aprendizagem foi contabilizada em dois trabalhos, bem como a construção significativa em conceitos, em outros dois. Essas pesquisas afirmaram que, a partir 
do ensino de tópicos de Astronomia, os alunos puderam alcançar níveis de aprendizagem mais sólidos, frente às teorias de Ausubel (MOREIRA, 1999).

h) Interdisciplinaridade:

Duas dissertações indicaram que o ensino de astronomia contribuiu para o desenvolvimento de atividades interdisciplinares.

Apesar do que já foi discutido anteriormente sobre a interdisciplinaridade, é importante destacar que esta deve ser utilizada como pressuposto estruturante das atividades proposta ou ainda como metodologia de ensino, e não como contribuição alcançada ao final do processo. Em outras palavras, o caráter interdisciplinar deve balizar a prática, conforme defende Fazenda (2005), e não apenas ser um objetivo a ser alcançado.

Demais contribuições do ensino de astronomia somaram uma citação cada e envolviam: auxilia o professor em suas aulas, propicia um diálogo construtivo em sala de aula, desenvolvimento de habilidades, aumento de interesse pela disciplina de física, astronomia como um bom instrumento de ensino, incentivo para a carreira científica ou astronômica, melhoria do ensino de física, aquisição de significados práticos, associação simples e direta da astronomia com a física, romper com concepções ingênuas sobre o universo, permitir a incorporação de elementos do discurso científico, desenvolvimento de visão crítica, boa aceitação por parte dos alunos.

Por fim, em uma pesquisa não foram encontradas contribuições referentes ao ensino de astronomia.

\section{CONSIDERAÇÕES FINAIS}

Com base em todas as discussões apresentadas, é possível observar que ainda existem poucos trabalhos voltados para o Ensino de Astronomia no Ensino Médio (27 produções). Até o presente estudo estas pesquisas estão restritas aos programas de mestrado, não havendo ainda a produção de pesquisas de doutorado.

De modo geral, todos os trabalhos tiveram como foco a sala de aula e, a maioria, voltada para os alunos, indicando uma preocupação maior com o desenvolvimento de atividades para a melhoria do processo de aprendizagem destes.

Com relação às metodologias de pesquisa adotadas pelos autores em suas pesquisas, observou-se que as atividades propostas utilizavam mais de uma estratégia simultaneamente, sendo que sequências didáticas e utilização de slides se destacam como as mais recorrentes.

A análise do caráter das pesquisas, em confronto com os conteúdos abordados e com as possíveis relações estabelecidas destes conteúdos com outras áreas do conhecimento, evidenciou que, em sua maioria, tais trabalhos são disciplinares e priorizam a física, sem estabelecer interfaces com outras áreas do conhecimento. Estas características estão em desacordo com os PCN (BRASIL, 1999) e PCN+ (BRASIL, 2002) e com as práticas interdisciplinares defendidas por Fazenda (2005), Lenoir (2008), Severino (2008) e Klein (2008). 
Apesar dos avanços propiciados pelas pesquisas que apresentaram características diferentes das apontadas acima, ainda existem muitas lacunas a serem exploradas e investigadas. Entre essas lacunas estão a ausência de um Ensino de Astronomia realmente interdisciplinar, como defende Dias e Rita (2008), a ausência de propostas envolvendo Ciência, Tecnologia e Sociedade (CTS), a falta de preocupação com os conceitos tecnológicos envolvidos com o desenvolvimento da Astronomia e ainda com uma alfabetização científica e tecnológica (ACT), defendidos por Aikenhead (1994), Bocheco (2011), Lorenzetti, Siemsen e Oliveira (2017).

Outra característica marcante das dissertações analisadas é a completa ausência de alusão aos conceitos de Química. Sabe-se que tópicos como origem dos elementos leves, reações nucleares, química quântica, química prébiótica, moléculas essenciais à vida e até a própria molécula de água são assuntos que apresentam grandes potencialidades em sala de aula, se trabalhados a partir do ponto de vista da Astronomia. Uma vez que os resultados mostram que, em grande parte das pesquisas, o fator motivacional foi determinante, pode-se explorar este fator em conjunto com as aulas de Química, de modo a avançar na superação de alguns dos desafios contemporâneos do ensino de ciências de modo geral, tais como o desinteresse do aluno.

Além disso, é possível, a partir desta perspectiva, caminhar ainda mais em busca da transposição das barreiras criadas entre as disciplinas e, alcançar então, uma prática interdisciplinar sólida, envolvendo a Química, a Biologia, a Física e ainda a História (da Ciência, da Tecnologia e da humanidade), Geografia, Filosofia, entre outras.

Partindo dessas conclusões, faz-se necessário propor que novas pesquisas sejam realizadas no âmbito do Ensino de Astronomia, com a investigação de novos temas ainda não pesquisados, em abordagens e perspectivas que fujam do tradicionalismo e da disciplinaridade ainda existentes em sala de aula, de modo a contribuir mais eficazmente para o ensino de ciências de forma geral. 


\title{
The research in Astronomy teaching to High School
}

\begin{abstract}
The present study has the objective of analysing the research in Astronomy teaching in High School, developed in postgraduate programs. To this assay, a "State of art" approach was employed, based on works found at Thesis and essay Capes database, geared towards High School. It was prioritized in these documents the research methodology, disciplinary or interdisciplinary feature, contents approached and established relations from these contents. Based on this analysis, it was observed that all of the researches are master's degree, from academic or professional postgraduate programs, focused on classroom. In relation to the approached contents, it was perceived a huge appreciation to Physics face to the other subjects, with few relations with topics of other knowledge areas, indicating gaps, mainly about chemistry contents. Thus, most of the pieces of research are classified as disciplinary, confronting PCN and PCN+. It was concluded, so, that a solid interdiscilinary focus is needed in the research on Astronomy teaching to High School, considering the inclusion of chemistry contents.
\end{abstract}

KEYWORDS: Astronomy teaching. High School. Chemistry. 


\section{REFERÊNCIAS}

ABREU, R. O. A realidade aumentada como recurso didático alternativo para o ensino de Astronomia: uma sequência didática para o estudo do Sistema Solar. 2015. Dissertação (Mestrado em Educação para Ciências e a Matemática). Instituto Federal de Educação, Ciência e Tecnologia de Goiás, Jataí- GO.

AIKENHEAD, G. S. STS education: international perspectives on reform. New York: Teacher's Colege Press, p. 47-59, 1994.

ALBRECHT, E. Diferentes metodologias aplicadas ao Ensino de Astronomia no Ensino Médio. 2008. Dissertação (Mestrado em Ensino de Ciências e Matemática) - Universidade Cruzeiro do Sul, São Paulo- SP.

ARAÚJO, D. C. C. Uma proposta para a inserção de tópicos de Astronomia indígena brasileira no Ensino Médio: desafios e possibilidades. 2014. Dissertação (Mestrado Profissional em Ensino de Ciências). Universidade de Brasília, BrasíliaDF.

Banco de Teses e Dissertações da Capes. http://bancodeteses.capes.gov.br/bancoteses/\#/. Acesso em: março de 2017.

BOCHECO, O. Parâmetros para a abordagem de evento no enfoque CTS. 2011. Dissertação (Mestrado em Educação Científica e Tecnológica) - Centro de Ciências em Educação, Universidade Federal de Santa Cataria, Florianópolis- SC.

BRASIL. Ministério da Educação (MEC). Secretaria de Educação Média e Tecnologia. Parâmetros Curriculares Nacionais: Ciências da natureza, matemática e suas tecnologias. Brasília: MEC/SEMTEC, 1999.

- Ministério da Educação (MEC), Secretaria de Educação e Tecnologia (SEMTEC). PCN+ Ensino Médio: Orientações Educacionais complementares aos Parâmetros Curriculares Nacionais. Ciências da natureza, matemática e suas tecnologias. Brasília: MEC/SEMTEC, 2002.

BRETONES, P. S. Disciplinas introdutórias de Astronomia nos cursos superiores. 1999. Dissertação (Mestrado em Geociências). Instituto de Geociências, UNICAMP, Campinas-SP.

CARRILHO, J. J. S. Astronomia no Ensino Médio- a Ciência e o Lúdico: desafiando e educando. 2015. Dissertação (Mestrado Profissional em Ensino de Astronomia). Universidade Estadual de Feira de Santana, Feira de Santana, BA. 
CHASSOT, A. I. Alfabetização científica: questões e desafios para a educação. Ijuí: Unijui, 2000.

COSTA, G. B. Uma abordagem humanística para o ensino de astronomia no Ensino Médio. 2005. Dissertação (Mestrado em Ensino de Ciências Naturais e Matemática) - Centro de Ciências Exatas e da Terra, Universidade Federal do Rio Grande do Norte, Natal- RN.

COSTA, L. B. Recursos Educacionais Abertos para o Ensino de Astronomia. 2015. Dissertação (Mestrado em Ensino) - Instituto de Astronomia, Geofísica e Ciências Atmosféricas, USP, São Paulo -SP.

DIAS, C. A. C. M.; RITA, J. R. S. Inserção de Astronomia como disciplina curricular no Ensino Médio. Revista Latino-Americana de Educação em Astronomia, n. 6, p. 55-65, 2008.

FAZENDA, I. C. A. Didática e Interdisciplinaridade. São Paulo: Ed. Papirus, 15. ed. 2005.

FERREIRA, N. S. As pesquisas denominadas "Estado da Arte". Educação e Sociedade, Campinas, n. 79, p. 257-272, 2002.

FRANCISCO C. A. Análise de dissertações e teses sobre o ensino de química nos programas de Pós-Graduação em ensino de ciências e matemática- Área 46/ Capes (2000-2008). 2011. Tese (Doutorado em Química), Universidade Federal de São Carlos, São Carlos- SP.

FRANCISCO JR. W. E.; FERREIRA, L. H.; HARTWIG, D. R. Experimentação Problematizadora: Fundamentos Teóricos e Práticos para a Aplicação em Salas de Aula de Ciências. Química Nova na Escola, 30, p. 34-41, 2008. Disponível em: http://qnesc.sbq.org.br/online/qnesc30/07-PEQ-4708.pdf. Acesso em: 20 de março de 2017.

GONÇALVEZ, M. P. Oficina astronômica: uma proposta de atividade utilizando materiais potencialmente significativos para o Ensino Médio. 2014. Dissertação (Mestrado Profissional em Ensino de Física). Instituto de Física. Universidade Federal do Rio Grande do Sul, Porto Alegre- RS. e Comunicação (TIC): proposta de abordagem e análise. 2015. Dissertação (Mestrado Profissional em Ensino de Astronomia). Universidade Estadual de Feira de Santana, Feira de Santana- BA. 
KEMPER, E. A inserção de tópicos de Astronomia como motivação para o estudo da Mecânica em uma abordagem epistemológica para o Ensino Médio. 2008. Dissertação (Mestrado Profissional em Ensino de Física). Instituto de Física, Universidade Federal do Rio Grande do Sul. Porto Alegre- RS.

KLEIN, J. T. Ensino interdisciplinar: didática e teoria. In: FAZENDA, I. C. A. (Org). Interdisciplinaridade: história, teoria e pesquisa. São Paulo: Ed. Papirus, p. 109132, 2008.

LANGHI, R. Educação em Astronomia: da revisão bibliográfica sobre concepções alternativas à necessidade de uma ação nacional. Caderno Brasileiro do Ensino de Física, v. 28, n. 22, p. 373-399, 2011.

LANGHI, R.; NARDI, R. Ensino de Astronomia: Erros conceituais mais comuns presentes em livros didáticos de Ciências. Caderno Brasileiro de Ensino de Física, Florianópolis, n. 24, v. 1, p. 87-111, 2007.

. Ensino de Astronomia no Brasil: educação formal, não formal e divulgação científica. Revista Brasileira de Ensino de Física, Florianópolis, v. 31, n. 4, 2009.

Formação de professores e seus saberes disciplinares em Astronomia Essencial nos anos iniciais do Ensino Fundamental. Revista Ensaio, Belo Horizonte, n. 2, p. 205-224, 2010.

LEÃO, D. S. Astronomia no Ensino Médio: um mini-planetário como recurso instrucional para a compreensão da Mecânica celeste. 2012. Dissertação (Mestrado Profissional em Ensino de Ciências). Instituto de Física. Universidade de Brasília, Brasília-DF.

LENOIR, Y. Didática e Interdisciplinaridade: uma complementaridade necessária e incontornável. In: FAZENDA, I. C. A. (Org). Interdisciplinaridade: história, teoria e pesquisa. São Paulo: Ed. Papirus, p. 45-75, 2008.

LORENZETTI, L. Estilos de pensamento em educação ambiental: uma análise a partir das dissertações e teses. 2008. Tese (Doutorado em Educação Científica e Tecnológica), Universidade Federal de Santa Catarina, Florianópolis- SC.

LORENZETTI, L., SIEMSEN, G. H., OLIVEIRA, S. Parâmetros de alfabetização científica e alfabetização tecnológica na Educação em Química: analisando a temática ácidos e bases. ACTIO: Docência em Ciência, Curitiba, v. 2, n. 1, p. 4-22, jan/jun. 2017 
MATTHEWS, M. R. História, Filosofia e Ensino de Ciências: a tendência atual de reaproximação. Caderno Catarinense de Ensino de Física, v. 12, n. 3, p. 164-214, dez. 1995.

MOREIRA, M. C. Teorias de aprendizagem. São Paulo: EPU, 1999.

MORETTI, R. L. Construção e aplicação de um material didático para inserção de Astronomia no Ensino Médio: uma proposta baseada nos referenciais curriculares do Rio Grande do Sul. 2012. Dissertação (Mestrado Profissional em Ensino de Física). Instituto de Física, Universidade Federal do Rio Grande do Sul, Porto AlegreRS.

MOTA, A. T. Ensino e Aprendizagem de Astronomia apoiado pelas Tecnologias da Informação e Comunicação. 2013. Dissertação (Mestrado Profissional em Ensino de Ciências). Universidade Federal de Itajubá, Itajubá- MG.

MOTA, A. T.; BONOMINI, I. A. M.; ROSADO, R. M. M., Inclusão de temas astronômicas numa abordagem inovadora do Ensino Informal de Física para estudantes do Ensino Médio. Revista Latino-Americana de Educação em Astronomia, n. 8, p. 7-17, 2009.

NEITZEL, C. L. V. Aplicação da Astronomia ao ensino de Física com ênfase em astrobiologia. 2006. Dissertação (Mestrado Profissional em Ensino de Física). Instituto de Física. Universidade Federal do Rio Grande do Sul, Porto Alegre- RS.

PEREZ, E. P. Caixa experimentoteca: uma proposta para o Ensino de Astronomia. 2015. Dissertação (Mestrado Profissional em Ensino de Física). Universidade Estadual Paulista, Presidente Prudente- SP.

RODRIGUES, R. L. Inserção da radiação cósmica de fundo no Ensino Médio através do uso de aplicativos Skyviewer e Planck Mission in virtual reality. 2015. Dissertação (Mestrado Profissional em Ensino de Física). Universidade Estadual de Feira de Santana, Feira de Santana, BA.

SANTIAGO, A. V. R. O potencial da observação no ensino de Astronomia: um estudo do conceito de energia. 2015. Dissertação (Mestrado em Ensino de Ciências). Universidade de São Paulo, São Paulo- SP.

SCHIMITT. C. E. O uso da Astronomia como instrumento para a introdução ao estudo de radiações eletromagnéticas no Ensino Médio. 2005. Dissertação (Mestrado Profissional em Ensino de Física). Instituto de Física. Universidade Federal do Rio Grande do Sul. Porto Alegre- RS. 
SEVERINO, A. J. O conhecimento pedagógico e a interdisciplinaridade: o saber como intencionalização da prática. In: FAZENDA, I. C. A. (Org). Interdisciplinaridade: história, teoria e pesquisa. São Paulo: Ed. Papirus, p. 30-44, 2008.

SIEMSEN, G. H.; LORENZETTI, L. A pesquisa em Ensino de Astronomia: analisando a produção acadêmica brasileira. In: ENCOTRO NACIONAL DE PESQUISA EM EDUCAÇÃO EM CIÊNCIAS, XI, 2017, Florianópolis. Anais... Florianópolis: ABRAPEC, 2017.

SILVA, F. S. Objetos-modelo no Ensino de Astronomia e no processo da transposição didática. 2011. Dissertação (Mestrado em Educação). Centro de Filosofia e Educação. Universidade de Caxias do Sul, Caxias do Sul- RS.

SILVA, F. P. O. Utilização de celulares como ferramenta no Ensino de Astronomia: aplicativo Star Chart como planetário. 2016. Dissertação (Mestrado Profissional em Ensino de Física). Universidade Federal do Vale do São Francisco, Juazeiro- BA.

SILVA, P. J. M. Através do Cosmos: uma proposta lúdica para o Ensino de Astronomia e Física. 2014. Dissertação (Mestrado em Ensino de Ciências Exatas). Centro de Ciências Exatas e Tecnologia. Universidade Federal de São Carlos, São Carlos- SP.

SILVA, S. M. Uma experiência de inserção de astronomia e física moderna no Ensino Médio a partir do Sol. 2015. Dissertação (Mestrado em Ensino de Ciências Naturais e Matemática). Universidade Federal do Rio Grande do Norte. Natal, RN.

SILVA, T. P. Nossa posição no Universo: uma proposta de sequência didática para o Ensino de Astronomia no Ensino Médio. 2015. Dissertação (Mestrado em Ensino de Ciências). Centro de Ciências Exatas, Universidade Federal do Espírito Santo, Vitória- ES.

SILVA, O. B.; QUEIROZ, S. L. Mapeamento da pesquisa no campo da formação de professores de Química no Brasil. In: ENCONTR NACIONAL DE PESQUISA EM EDUCAÇÃO EM CIÊNCIAS, IX, 2013, Águas de Lindóia. Anais... Águas de Lindóia: ABRAPEC, 2013.

SOBRINHO, A. A. O olho e o céu: contextualizando o ensino de Astronomia no nível Médio. 2005. Dissertação (Mestrado em Ensino de Ciências Naturais e Matemática)- Centro de Ciências Exatas e da Terra, Universidade Federal do Rio Grande do Norte, Natal- RN. 
VALENTE, J. A. S. A construção de conceitos relacionados com os movimentos Terra- Lua- Sol por alunos da E.J.A. à luz da Teoria Histórico-Cultural. 2007. Dissertação (Mestrado em Educação em Ciências e Matemática). Universidade Federal do Pará, Belém- PA.

ZABALA, A. A prática educativa: como ensinar. Porto Alegre: Editora Artmed, 1998.

Recebido: 29 jul. 2017

Aprovado: 18 dez. 2017

DOI: 10.3895 /actio.v2n3.6838

Como citar:

SIEMSEN, G. H.; LORENZETTI, L. A Pesquisa em Ensino de Astronomia para o Ensino Médio. ACTIO,

Curitiba, v. 2, n. 3, p. 185-207, out./dez. 2017. Disponível em: <https://periodicos.utfpr.edu.br/actio>. Acesso em: XXX.

Correspondência:

Giselle Henequin Siemsen

Rua Germânia, 226, casa 17 - Cajuru, Curitiba/PR.

Direito autoral: Este artigo está licenciado sob os termos da Licença Creative Commons-Atribuição 4.0

Internacional.

(c) (i) 